\title{
Bacterial characteristics and their antibiotic sensitivity pattern in Sri Lankan diabetic foot ulcers
}

\author{
WSMKJ Senanayake ${ }^{1}$, LAK Samarasekara ${ }^{2}$, Ranil Fernando ${ }^{3}$, WA Kirthi Weerawardena ${ }^{4}$ \\ ${ }^{1}$ Department of Surgery, Faculty of Medicine and Allied Health Sciences, ${ }^{2}$ Department Surgery, \\ General Hospital, Kegalle, ' Department of Surgery, Faculty of Medicine, Ragama, ${ }^{4}$ \\ Department of Surgery, Teaching Hospital Anuradhapura
}

\begin{abstract}
Introduction: The pathology behind the poor healing of diabetic foot ulcers is multifactorial. A major cause for the deterioration of diabetic foot disease is infection. It needs thorough understanding of the bacteriology of diabetic foot ulcers in order to achieve a good control of infection. The bacteriology would defer from one ethnic community to other due to the variations of antibiotic policies and various genetic and environmental factors. There are no published data in the English literature with regard to the bacteriology of diabetic foot ulcers among Sri Lankan.
\end{abstract}

Material and methodology: A descriptive cross sectional study was performed from $15^{\text {th }}$ of April 2010 to $15^{\text {th }}$ of October 2010. All the patients who admitted with grade 2 to 4 (Meggit Wagner grading) diabetic foot ulcers were included. Swab cultures were taken from a deeper layer of slough/exudates before administration of systemic antibiotics. Identification of microorganism done by an experienced medical microbiologist and the sensitivity pattern was performed by Kirby Baurer disc diffusion method. Anaerobic cultures were not done due to lack of resources.

Results: Fifty three patients with diabetic foot ulcers, age ranging from 33 to 78 years (mean 59, SD $\pm 12.5)$ met the inclusion criteria $45(85 \%)$ male and $8(15 \%)$ females).All swabs were positive for the culture. Single microbial isolates were commoner ( $\mathrm{n}$ $=40,75 \%$ ) than poly microbial isolates ( $n=13,25 \%$ ). The commonest organism was pseudomonas spp ( $n=35,66 \%)$, followed by coli forms ( $n=16,30 \%)$ and staphylococcus aurius ( $n=10,20 \%$ ). Most of the pseudomonas spp is sensitive to Amikacine (85\%) and most of coliforms and staphyloccus aurius are sensitive to Amikacine (81\%) and Fusidic acid (100\%) respectively.

Conclusion: The most common etiology for the diabetic foot infection among Sri Lankan is pseudomonas spp, and $85 \%$ of them are sensitive to Amikacine. Current study revealed the bacteriological characteristic among the Sri Lankan Diabetic foot disease for the first time. Data will be helpful to update guideline in the management of diabetic ulcers.

\section{Introduction}

Diabetic mellitus is the commonest cause of foot ulceration among Sri Lankan ${ }^{1}$. The prevalence of diabetic mellitus has increased over the past decade by four fold and the prevalence among Sri Lankan urban population is $16.4 \% \%^{2,3}$. The risk of lower limb amputation is 15 to 46 times higher in diabetic than who are not having diabetic mellitus ${ }^{4,5}$. The health care expenditure is enormous in the management 
of diabetic foot disease. Prevention of foot ulceration in diabetes is the most appropriate measure. However once the ulceration occurs the prevention of further deterioration and measures to accelerate healing should be undertaken promptly to prevent limb threatening and the life threatening complications. Foot infection is the most common complication of the diabetic foot ulcers and plays a major role in development of wet gangrene ${ }^{6}$. Hence early identification of causative organism and antibiotic sensitivity pattern and administration of appropriate antibiotic prevent further complication ${ }^{7.8}$. Pseudomonas spp., Enterococcus spp. \& Proteus spp. carry a special role and are responsible for continuing and extensive tissue destruction with the poor blood circulation of the foot and a high frequency of anaerobic infection has also been reported ${ }^{9}$. The bacterial characteristic could be deferent from one ethnic community to other due to variations of antibiotic polices and other factors such as environmental and genetic factors. In Sri Lankan setting there are no data in the English literature with regard to the bacteriological characteristic of diabetic foot infection. Current study we aim to identify the bacteriological characteristic of diabetic foot infection among Sri Lankan for the first time.

\section{Material and methodology}

A descriptive cross sectional study was performed from $15^{\text {th }}$ of April 2010 to $15^{\text {th }}$ of October 2010. All the patients who admitted to the department of general surgery with grade 2 to 4 (Meggit Wagner grading) diabetic foot ulcers were included ${ }^{10}$. Patients who were given systemic antibiotics and the patients with osteomyelitis were excluded. Swab cultures were taken from a deeper layer of slough/exudates before administration of systemic antibiotics. Specimens were cultured on appropriate culture medias. Identification of microorganism done by an experienced medical microbiologist by gram staining and the sensitivity pattern was performed by Kirby Baurer disc diffusion method according to National Committee for Clinical Laboratory Standards (NCCLS) guidelines $^{11}$. Anaerobic cultures were not done due to lack of resources.

\section{Results}

Fifty three patients with diabetic foot ulcers, age ranging from 33 to 78 years (mean 59, SD \pm 12.5 ) met the inclusion criteria (45 (85\%) male and 8 (15\%) females).All swabs were positive for the culture. Single microbial isolates were commoner ( $\mathrm{n}$ $=40,75 \%)$ than poly microbial isolates $(n=13,25 \%)$. The commonest organism was pseudomonas spp $(n=35,66 \%)$, followed by coli forms ( $n=16,30 \%)$ and staphylococcus aurius ( $n=10,20 \%$ ). Most of the pseudomonas spp is sensitive to Amikacine (85\%) and most of coliforms and staphyloccus aurius are sensitive to Amikacine (81\%) and Fusidic acid $(100 \%)$ respectively. Forty percent of the staphylococcus aurius are methiciline resistant. The relative frequencies of the isolated micro organisms were summarized in the table 1 and the sensitivity pattern for the commonly used antibiotics were summarized for the each organism in the table 2, 3 , 4,5 .

\begin{tabular}{|l|c|}
\hline \multicolumn{1}{|c|}{ Bacterial types } & $\begin{array}{c}\text { Relative } \\
\text { frequency }\end{array}$ \\
\hline 1.Pseudomanas sp. & $66 \%$ \\
\hline 2.coliforms & $30 \%$ \\
\hline 3.Staphylococus aureus & $11 \%$ \\
\hline 4.Acinetobacter sp. & $7 \%$ \\
\hline 5.Proteus & $2 \%$ \\
\hline
\end{tabular}

Table 1. Relative frequencies of the isolated microorganism 


\begin{tabular}{|l|c|c|c|}
\hline \multicolumn{1}{|c|}{ Antibiotic } & Sensitive & Resistance & $\begin{array}{c}\text { Intermediate } \\
\text { Sensitive }\end{array}$ \\
\hline 1.Amikacine & $85 \%$ & $11.4 \%$ & $2 \%$ \\
\hline 2.Ceftazidime & $79 \%$ & $17.6 \%$ & $2.9 \%$ \\
\hline 3.Ciprofloxacin & $48 \%$ & $52 \%$ & \\
\hline 4.Gentamicin & $74.2 \%$ & $25.7 \%$ & \\
\hline 5.Netilmicin & $74 \%$ & $25.7 \%$ & \\
\hline 6.Ticarcillim & $50 \%$ & $50 \%$ & \\
\hline 7.Aztreonam & $67.8 \%$ & $21.4 \%$ & $10.7 \%$ \\
\hline
\end{tabular}

Table 2. Antibiotic sensitivity pattern of the pseudomonas spp.

\begin{tabular}{|l|c|c|c|}
\hline \multicolumn{1}{|c|}{ Coliforms } & Sensitive & Resistance & $\begin{array}{c}\text { Intermediate } \\
\text { Sensitive }\end{array}$ \\
\hline 1.Amikacin & $81 \%$ & $12.5 \%$ & $6.25 \%$ \\
\hline 2.Ceftazidime & $62.5 \%$ & $25 \%$ & $12.5 \%$ \\
\hline 3.Ciprofloxacin & $26.6 \%$ & $66.6 \%$ & $6.6 \%$ \\
\hline 4.Gentamicin & $53.3 \%$ & $40 \%$ & $6.6 \%$ \\
\hline 5.Co-Amoxyclave & $7.6 \%$ & $84.6 \%$ & $7.6 \%$ \\
\hline 6.Cefotaxime & $46.6 \%$ & $53.3 \%$ & \\
\hline 7.Netilmicin & $64.2 \%$ & $35.7 \%$ & \\
\hline 8.Aztreonum & $66 \%$ & $22.2 \%$ & $11.1 \%$ \\
\hline
\end{tabular}

Table 3. Antibiotic sensitivity pattern of the isolated coliforms

\begin{tabular}{|l|c|c|}
\hline \multicolumn{1}{|c|}{$\begin{array}{c}\text { Staphylococcus } \\
\text { aureus }\end{array}$} & Sensitive & Resistance \\
\hline 1.Gentamicin & $50 \%$ & $50 \%$ \\
\hline 2.Cloxacillin & $30 \%$ & $70 \%$ \\
\hline 3.Co-Amoxyclave & $20 \%$ & $80 \%$ \\
\hline 4.Co-trimoxazole & $50 \%$ & $50 \%$ \\
\hline 5.Fusidic Acid & $87 \%$ & $12.5 \%$ \\
\hline 6.Vancomicin & $100 \%$ & \\
\hline 7.Erithromicin & $50 \%$ & $50 \%$ \\
\hline 8. methiciline & $60 \%$ & $40 \%$ \\
\hline
\end{tabular}

Table 4. Antibiotic sensitivity pattern of the isolated staphylococcus aureus 


\begin{tabular}{|l|c|c|}
\hline \multicolumn{1}{|c|}{$\begin{array}{c}\text { Acinetobacter } \\
\text { sp. }\end{array}$} & Sensitive & Resistance \\
\hline 1.Amikacin & $75 \%$ & $25 \%$ \\
\hline 2.Ceftazidime & $50 \%$ & $50 \%$ \\
\hline 3.Ciprofloxacin & $50 \%$ & $50 \%$ \\
\hline 4.Gentamicin & $33.3 \%$ & $66.6 \%$ \\
\hline 5.Netilmicin & $66 \%$ & $33 \%$ \\
\hline 6.Aztreonam & $66 \%$ & $33.3 \%$ \\
\hline
\end{tabular}

Table 5. Antibiotic sensitivity pattern of acenatobacter spp

\section{Discussion}

The trio of problem leading on to the diabetic foot is neuropathy, vascular changes and infections, which constitute the diabetic foot syndrome $e^{12,13}$. Neuropathy and vascular changes almost not modifiable once they established. However the infection can be prevented and it is treatable, if it is early diagnosed and the bacterial characteristic such as antibiotic sensitivity pattern identified precisely.

There are no published data on the pattern of microbial flora and their antibiotic sensitivity with regard to the Sri Lankan setting. Therefore the current study is an important turning point for the updating guidelines on management of diabetic foot disease and will be a good trigger for further studies.

There is a significant male preponderance in the occurrence of diabetic foot ulcers among Sri Lankans (85\%). The increased incidence of diabetic foot ulcers among males were noted in several other series studies too $0^{9,13,14}$. The etiology for higher incidence of diabetic foot ulcers among males need to be evaluated further.

Diabetic foot ulcer infection is polymicrobial ${ }^{4,6,8,9,13,14}$. However in the current study single isolates were commoner than the polymicrobial etiology. The different could be due to variations in the sample collection methods and antibiotic usage before sample collection.

The commonest organism isolated in current study was pseudomonas spp, and in the literature it was found in higher frequencies but few studies had the highest incidence ${ }^{9,13,14}$. Pseudomonas spp may produce severe tissue damage and never be disregard as insignificant in diabetic foot ulcers $^{14}$. Major problem of pseudomonas spp is that is shows a high degree of resistance to broad spectrum antibiotics. Carbopenum is often used to treat the pseudomonas infection and however some strains produces Metalo B Lactamase (MBL), which make resistance to most commonly used antibiotics such as B lactams, amino glycosides and fluroquinolones ${ }^{15}$. Current study $85 \%$ of the isolates is sensitive to amikacine and $79 \%$ are sensitive to ceftazidime. Higher prevalence of pseudomonas spp in Sri Lankan diabetic foot ulcers should be considered as a significant health care problem and prompt bacteriologic studies aiming specially at identification of resistant strains should be carried out. Amikacine seems to be the drug of choice in infected diabetic ulcers in Sri Lankan setting.

Coli forms were isolated as the second commonest organism (30\%). Coliforms are a predominant oraganism to be isolated in other series too ${ }^{13}$. It is interesting to note that recent isolation of inducible Amp C B-lactamase producing Enterobacter aerogenes from a diabetic foot ulcer in a Sri lankan patient with diabetic foot ulcer ${ }^{16}$. Emergence resistant coli form strain should be born in mind when treating diabetic foot infections. Only $7 \%$ of coliforms are sensitive to co-amoxiclav and this could be attributing to irrational antibiotic usage. All the patients in our study group have had oral antibiotics before coming to hospital. 
Staphylococcus aurious was isolated in 11\% of the patients and the $40 \%$ of them are methiciline resistant. The incidence of the MRSA in diabetic foot disease is comparable with the literature reported ${ }^{17}$. All the staphylococci were sensitive to vancomicine in the current study.

Acenotobacter spp was isolated in $7 \%$ of the patients and this seems to be an emerging infection among Sri Lankan diabetic with foot ulcers. Resistant gram negative organism isolated together with Acenatobacter, term as ESCAPPM" organisms (Enterobacter, Serratia, Citrobacter freundii, Acinetobacter, Providencia spp, Proteus, Morganella) (18). Proteus spp, was isolated only in $2 \%$ of patients. Meny of the acenetobacter spp are resistant to commonly used antibiotics (table 5).

We have not done the assessment of fungal flora and the anerobes due to the lack laboratory facilities and it needs further study to assess anaerobes and fugal flora which have important role in diabetic footinfection.

\section{Conclusion}

Common organisms that cause diabetic foot ulceration among Sri Lankans are pseudomonas spp, coli forms, staphylococcus aurious, and acenotobacter spp. The high prevalence of pseudomonas spp in Sri Lankan diabetic foot ulcers should be addressed. It needs further epidemiological and genetic studies to identify antibiotic resistant strains.

\section{References}

1. Fernando DIB.The prevalence of neuropathic foot ulceration in Sri Lankan diabetes patients. Ceylon Med J 1996;41 96-98

2. Katulanda P, Constantine GR,, Mahesh JG, et al. Prevalence and projections of diabetes and pre diabetes in adults in Sri Lanka -Sri Lanka diabetes cardiovascular study(SLDCS), diabetic medicine,25(9);1062:1069

3. Malavige GN , de Alwis NM, Siribaddana.SH, et al. increasing diabetes and vascular risk factors in sub-urban Sri Lankan population. Diab Res clin pract 2002;57:143-145

4. Sarkar PK, Ballantyne S. Management of leg ulcers. Postgrad Med J 2000;76:674-82.

5. Fahey $T$, Sadaty A, Jones W. Diabetic impairs the late inflammatory response to wound healing. J Surg Res 1991;50:308-13.

6. Smith JMB, Payne JE, Berue TV. Diabetic foot lesions of skin and soft tissue infections of surgical importance. Chapter 14. In: The surgeons Guide to Antimicrobial Chemotherapy 2002;218-21.

7. Bailey TS, Yu HM, Rayfield EJ. Patterns of foot examination in a diabetic clinic. Am J Med 1985;78:371-4.

8. Frykberg RG. Diabetic foot ulcers: current concepts. J Foot Ankle Surg 1998;37:440-6.

9. Alavi SM, Khosravi AD, Sarami A, Dashtebozorg A, Montazeri EA. Bacteriologic study of diabetic foot ulcer. Pak J Med Sci 2007 : 23; 681-684

10. Wagner FW. The diabetic foot. Orthopedics 1987;10:163-72. 
11. Performance standards for antimicrobial susceptibility testing. 12th informational supplement. NCCLS document M100-\$12,22, No.1,Pennsylvania, USA, 2002

12. Meade JW, Muller CB. Major infections of the foot.Med Times 1968;96:154-165.

13. Anandi C, Alaguraja D, Natarajan V, Ramanathan M, Subramaniam CS, Thulasiram M, Sumithra S. Bacteriology of diabetic foot lesions. Indian Journal of Medical Microbiology, (2004) 22 (3):175-178

14. , Garg A, Bhatia S, Attri AK, Chander J. Spectrum of microbial flora in diabetic foot ulcers. Indian J Pathol Microbiol 2008;51:204-8

15. Murugan S, Laxshmi RB, Devi PU, Mani KR. Prevalence and susceptibility pattern of metallo B lactamase producing pseudomonas aeruginosa in diabetic foot infection. Intl.J.Microbial. Res 20101;(3):123-128
16. Corea EM, Bandara PLL. Isolation of inducible Amp C B-lactamase producing Enterobacter aerogenes from a diabetic foot ulcer Ceylon MedJ 2010 55;3:95

17. Tentolouris N, Jude EB, Smirnof I, Knowles EA, Boulton AJ. Methicillin-resistant Staphylococcus aureus: an increasing problem in a diabetic foot clinic. Diabet Med. 1999 16(9):767-71.

18. Yates C, May K, Hale T, Allard B, Rowlings N, Freeman A, Harrison J, McCann J, Wraight P. Wound chronicity, inpatient care, and chronic kidney disease predispose to MRSA infection in diabetic foot ulcers. Diabetes Care. 2009 Oct;32(10):1907-9.

\section{Authors}

- WSMKJ Senanayake

Senior Lecturer, Department of Surgery, Faculty of Medicine and Allied Health Sciences

- LAK Samarasekara

Consultant Surgeon, Department Surgery, General Hospital, Kegalle

- Ranil Fernando

Consultant Surgeon, Department of Surgery, Faculty of Medicine, Ragama

- WA Kirthi Weerawardena

Consultant Surgeon, Department of Surgery, Teaching Hospital Anuradhapura 